\title{
Sustained reduction in antibiotic consumption in a South African public sector hospital: Four-year outcomes from the Groote Schuur Hospital antibiotic stewardship programme
}

\author{
T H Boyles, ${ }^{1}$ MA, BM BCh (Oxon), MRCP, MD, Cert ID (SA), DTM\&H; V Naicker, ${ }^{2}$ BSc (Pharm); N Rawoot, ${ }^{2}$ BPharm; \\ P J Raubenheimer, ${ }^{3} \mathrm{MB}$ ChB, FCP; B Eick, ${ }^{4} \mathrm{MB}$ ChB; M Mendelson, ${ }^{1}$ BSc, MBBS, PhD, FRCP, DTM\&H \\ ${ }^{1}$ Division of Infectious Diseases and HIV Medicine, Department of Medicine, Groote Schuur Hospital and Faculty of Health Sciences, \\ University of Cape Town, South Africa \\ ${ }^{2}$ Pharmacy Department, Groote Schuur Hospital, Cape Town, South Africa \\ ${ }^{3}$ Division of General Internal Medicine, Department of Medicine, Groote Schuur Hospital and Faculty of Health Sciences, University of \\ Cape Town, South Africa \\ ${ }^{4}$ Groote Schuur Hospital, Cape Town, South Africa
}

Corresponding author: T H Boyles (tomboyles@yahoo.com)

\begin{abstract}
Background. Overuse of antibiotics has driven global bacterial resistance to the extent that we have entered a post-antibiotic era, where infections that were once easily treatable are now becoming untreatable. Efforts to control consumption have focused on antibiotic stewardship programmes (ASPs), aimed at optimising use.

Objective. To report antibiotic consumption and cost over 4 years from a public hospital ASP in South Africa (SA).

Methods. A comprehensive ASP comprising online education, a dedicated antibiotic prescription chart and weekly dedicated ward rounds was introduced at Groote Schuur Hospital, Cape Town, in 2012. Electronic records were used to collect data on volume and cost of antibiotics and related laboratory tests, and to determine inpatient mortality and 30-day readmission rates. These data were compared with a control period before the intervention.

Results. Total antibiotic consumption fell from 1046 defined daily doses/1 000 patient days in 2011 (control period) to 868 by 2013 and remained at similar levels for the next 2 years. This was driven by reductions in intravenous antibiotic use, particularly ceftriaxone. Inflation-adjusted cost savings on antibiotics were ZAR3.2 million over 4 years. Laboratory tests increased over the same period with a total increased cost of ZAR0.4 million. There was no significant change in mortality or 30-day readmission rates.

Conclusions. The effects of a comprehensive ASP on medical inpatients at a public sector hospital in SA were durable over 4 years, leading to a reduction in total antibiotic consumption without adverse effect. When increased laboratory costs were offset there was a net cost saving of ZAR2.8 million.
\end{abstract}

S Afr Med J 2017;107(2):115-118. DOI:10.7196/SAMJ.2017.v107i2.12067

The global increase in bacterial resistance to antibiotics has resulted in a tipping point towards a post-antibiotic era, where common infections that were previously easily treated now require antibiotics of last resort or are de facto untreatable. ${ }^{[1-3]}$ South Africa (SA) has seen an alarming increase in rates of extended-spectrum beta-lactamase (ESBL)-producing Gram-negative bacteria ${ }^{[4-5]}$ and carbapenem-resistant Enterobacteriaceae (CRE), which have been reported from every province. ${ }^{[6]}$ The main driver of antibiotic resistance is overuse and misuse of antibiotics. ${ }^{[7-9]}$ Poor infection prevention practice in healthcare settings fuels the spread of resistant bacteria, which cause healthcare-associated infections in SA and abroad. ${ }^{[10,11]}$ Antibiotic stewardship programmes (ASPs), ${ }^{[3,12]}$ which aim to optimise the use of antibiotics, combine targeted interventions with surveillance, guidelines, education, and monitoring and evaluation through audit. ${ }^{[13]}$ In 2012, we reported the results of a pilot ASP at Groote Schuur Hospital, Cape Town, which showed for the first time that antibiotic stewardship (AS) could be successfully introduced into the SA public sector. ${ }^{[14]}$

In this article, we demonstrate that when rolled out on a greater scale this programme can deliver sustained reductions in antibiotic consumption, and achieve cost-savings within 4 years that could pay for the programme itself.

\section{Methods \\ Setting}

Groote Schuur Hospital, the 945-bed tertiary academic teaching hospital of the University of Cape Town, offers medical, surgical, obstetric, psychiatric and emergency care to Cape Town's Metro West population. Four wards are dedicated to long-stay ( $>48$ hours) acute general internal medicine admissions, and consultant-led antibiotic prescribing is the norm.

\section{AS intervention}

The activities of the ASP have been presented previously in 2012. ${ }^{[14]}$ Briefly, we instituted a dedicated antibiotic prescription chart and dedicated antibiotic stewardship ward rounds, which alternated weekly between two medical wards. Rounds were led by an infectious diseases subspecialist, and the team included medical microbiologists, pharmacists, infection prevention control practitioners and the junior clinicians directly responsible for the patients' care. Each patient on a ward was reviewed individually and a pertinent history was given regarding antibiotic prescribing and the use of intravenous cannulas and urinary catheters. Each case was then discussed, an action plan agreed upon and education around AS imparted. 
There have been important changes to the ASP since 2012. Ward rounds have been extended to cover all four of the internal medicine wards on a weekly basis, and as institutional knowledge has increased, ward rounds have been able to focus on smaller numbers of patients with complex problems rather than including every patient on all four wards. Initially, certain antibiotics were restricted and required release by a microbiologist or infectious diseases physician; these were intravenous ciprofloxacin, carbapenems, piperacillintazobactam, colistin, tigecycline, aztreonam, linezolid and vancomycin. In March 2013 the restrictions for intravenous ciprofloxacin, ertapenem, piperacillin-tazobactam and vancomycin were lifted, although release by the consultant responsible for the patient was still required.

\section{Antibiotic consumption}

Electronic pharmacy dispensing records were used to calculate consumption and cost of antibiotics, with oral and parenteral formulations of the same antibiotic treated separately. Antibiotics that had been used to treat mycobacterial, parasitic and fungal infections, including co-trimoxazole, were excluded. Antibiotic use during the intervention period (1 January 2012 - 31 December 2015) was compared with that during the control period (1 January 2011 - 31 December 2011). Consumption of antibiotics was converted into defined daily doses (DDDs) according to the World Health Organization standard. All costs were adjusted for inflation using the SA Consumer Price Index (CPI) (December $2012=100)$.

\section{Laboratory tests}

The number and costs of blood culture (BC), full blood count (FBC), white blood cell count differential (WBC), C-reactive protein (CRP) and procalcitonin (PCT) requests were calculated from the National Health Laboratory Service database.

\section{Patient data}

Data on inpatient mortality and hospitalwide, all-cause readmission to Groote Schuur Hospital within 30 days of discharge were obtained from the hospital electronic admissions database (Clinicom).

\section{Ethics}

The study was approved by the Human Research Ethics Committee of the Faculty of Health Sciences, University of Cape Town (ref. no. 004/2012).

\section{Results}

Change in antibiotic consumption

The total consumption of antibiotics on the four wards in 2011 was $1046 \mathrm{DDD} / 1000$ patient bed days. There was no change overall in 2012, but in each of the subsequent years there was a decrease of approximately $18 \%$ compared with 2011. This reduction was driven mainly by decrease in intravenous antibiotic consumption, which fell by 25 $30 \%$ in the years $2013-2015$, compared with 2011. By contrast, there was very little

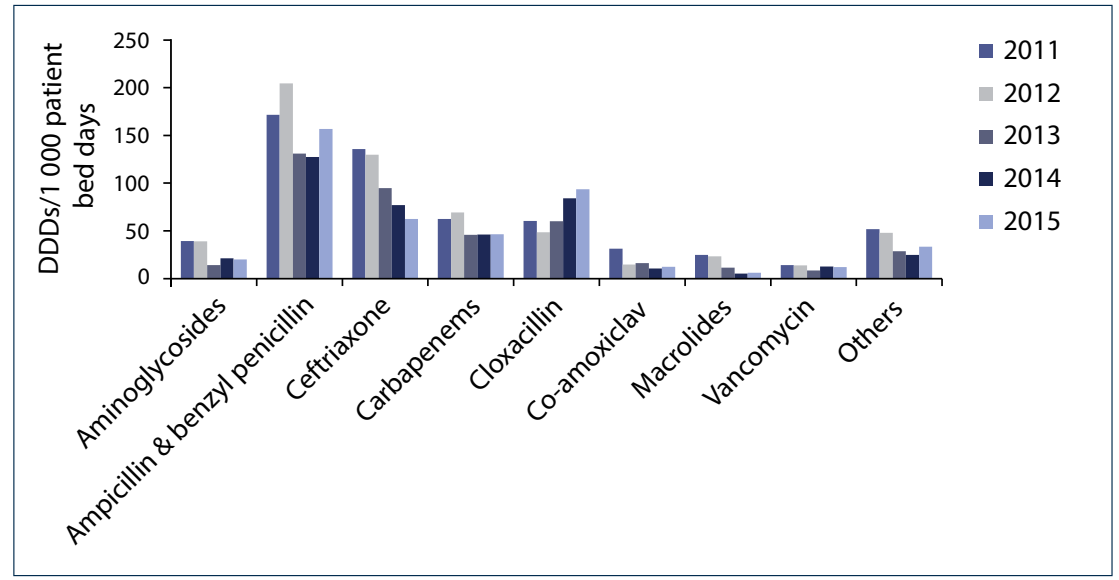

Fig. 1. Changes in use of intravenous antibiotics on four medical wards over 5 years (2012 - 2015 and the control period 2011).

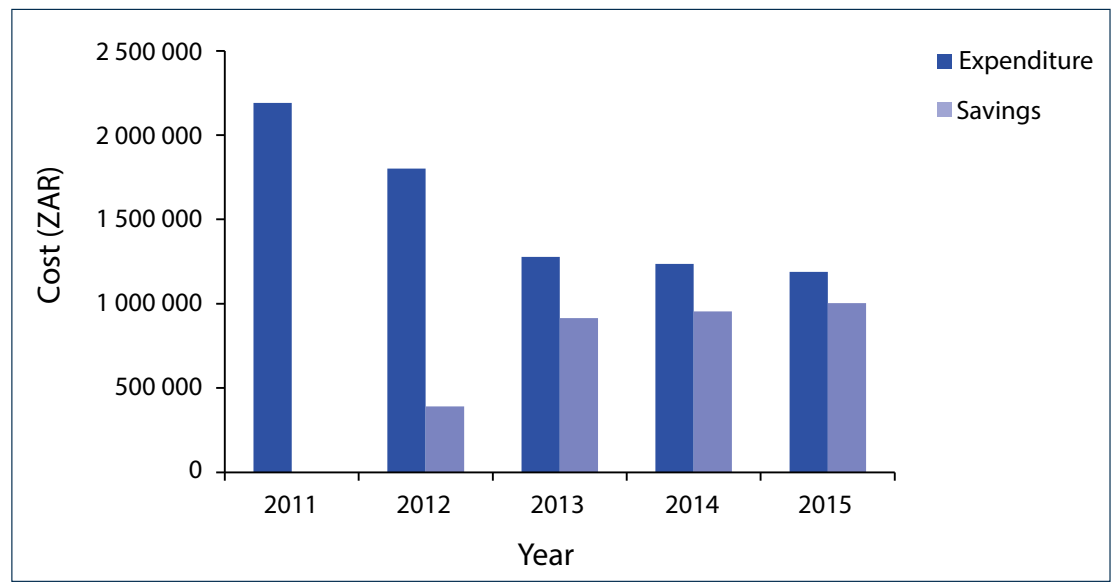

Fig. 2. Direct cost of antibiotics used on four medical wards over 5 years (2012 - 2015 and the control period 2011). Costs adjusted for inflation using SA CPI: December $2012=100$.

Table 1. Antibiotic use on four medical wards over 5 years (2012 - 2015 and the control period 2011)

\begin{tabular}{|c|c|c|c|c|c|c|}
\hline Year & $\begin{array}{l}\text { All antibiotics, } \\
\text { DDDs/ } 1000 \\
\text { patient bed days }\end{array}$ & $\begin{array}{l}\text { Change in all } \\
\text { antibiotics since } \\
2011, \%\end{array}$ & $\begin{array}{l}\text { Intravenous } \\
\text { antibiotics, DDDs/ } \\
1000 \text { patient bed } \\
\text { days }\end{array}$ & $\begin{array}{l}\text { Change in } \\
\text { intravenous } \\
\text { antibiotics since } \\
2011, \%\end{array}$ & $\begin{array}{l}\text { Oral antibiotics, } \\
\text { DDDs/ } 1000 \\
\text { patient bed days }\end{array}$ & $\begin{array}{l}\text { Change in oral } \\
\text { antibiotics since } \\
2011, \%\end{array}$ \\
\hline 2011 & 1046 & & 592 & & 454 & \\
\hline 2012 & 1061 & +1.5 & 591 & -0.1 & 470 & +3.5 \\
\hline 2013 & 868 & -17.1 & 411 & -31 & 457 & +0.7 \\
\hline 2014 & 843 & -19.4 & 409 & -31 & 434 & -4.4 \\
\hline 2015 & 864 & -17.4 & 443 & -25 & 421 & -7.3 \\
\hline
\end{tabular}


Table 2. Direct cost of antibiotics used on four medical wards over 5 years (2012 - 2015 and the control period 2011)

\begin{tabular}{llll}
\hline Year & Cost $^{*}($ ZAR $)$ & $\begin{array}{l}\text { Decrease from } \\
\mathbf{2 0 1 1}^{*}(\mathbf{Z A R})\end{array}$ & $\begin{array}{l}\text { Decrease } \\
\text { from 2011, \% }\end{array}$ \\
\hline 2011 & 2191594 & & \\
2012 & 1800808 & 390786 & 18 \\
2013 & 1277481 & 914113 & 42 \\
2014 & 1236797 & 954796 & 44 \\
2015 & 1187942 & 1003652 & 46 \\
${ }^{*}$ Costs adjusted for inflation using the SA CPI: December 2012 = 100.
\end{tabular}

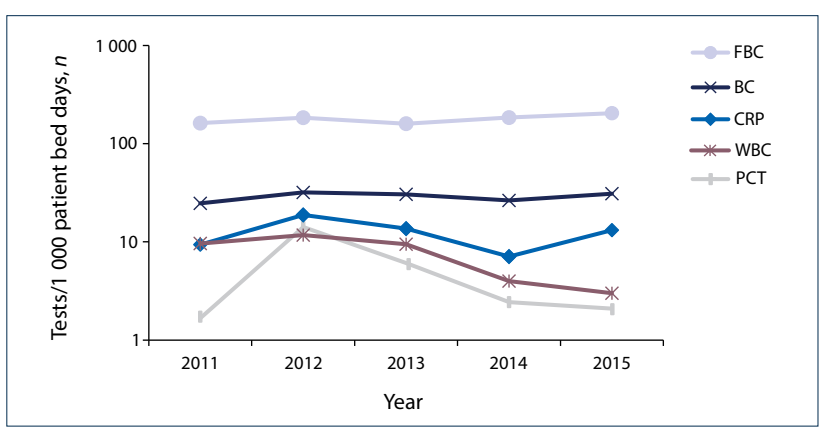

Fig. 3. Numbers of requests for infection-related investigations from four medical wards over 5 years (2012 - 2015 and the control period 2011).

difference in consumption of oral antibiotics over this period (Table 1). The change in consumption of individual intravenous antibiotics is shown in Fig. 1. There were consistent reductions in most antibiotics, notably a $54 \%$ reduction in use of ceftriaxone between 2011 and 2015. An exception was cloxacillin, which increased by $56 \%$ over the same period, coinciding with increased education around the correct recommended dose.

\section{Change in antibiotic cost}

The inflation-adjusted cost of antibiotics was ZAR2 191594 in 2011 and lower for each of the subsequent years. By 2015, inflationadjusted cost was $46 \%$ lower than in 2011 (Table 2, Fig. 2). The total saved over the 4 years was ZAR3 263340.

\section{Laboratory tests}

Fig. 3 shows the trend in use of infection-related laboratory tests over the study period. The number of requests for FBCs and BCs rose from 162 to 204 , and 24.7 to 30.9 per 1000 patient bed days, respectively. PCT requests peaked in 2012 shortly after their introduction and subsequently declined year on year. The inflation-adjusted cost of these tests was ZAR504 333 in 2011, peaking at ZAR721 280 in 2012 ( $43 \%$ above baseline), before falling to $<15 \%$ above baseline for the subsequent 3 years (Table 3 ). The total extra spending on tests over 4 years was ZAR401 903.

\section{Inpatient mortality and readmission rates}

The total number of patient days increased over the duration of the study from $<39000$ in 2011 to almost 43000 in 2015. During this time the mortality rate remained constant at 0.12 deaths/admission and only non-significant changes in the readmission rate were observed (Table 4).

\section{Discussion}

This study confirms that the introduction of an ASP into a public sector hospital in SA is feasible, and can produce a sustained reduction
Table 3. Cost of infection-related blood tests (BC, FBC, WBC, CRP and PCT) requested from four medical wards over 5 years (2012 - 2015 and the control period 2011)

\begin{tabular}{llll}
\hline Year & Costs $^{*}(\mathbf{Z A R})$ & $\begin{array}{l}\text { Increase from } \\
\mathbf{2 0 1 1}^{*}(\mathbf{Z A R})\end{array}$ & $\begin{array}{l}\text { Increase from } \\
\mathbf{2 0 1 1} \mathbf{\%}\end{array}$ \\
\hline 2011 & 504333 & & \\
2012 & 721280 & 216947 & 43 \\
2013 & 575875 & 71542 & 14 \\
2014 & 546936 & 42603 & 8 \\
2015 & 575144 & 70811 & 14 \\
${ }^{*}$ Costs adjusted for inflation using the SA CPI: December 2012 = 100.
\end{tabular}

Table 4. Patient outcomes on four medical wards over 5 years

\begin{tabular}{lllll}
\hline Year & $\begin{array}{l}\text { Inpatient } \\
\text { days }\end{array}$ & $\begin{array}{l}\text { Average } \\
\text { length of } \\
\text { stay (days) }\end{array}$ & $\begin{array}{l}\text { Mortality } \\
\text { rate, deaths/ } \\
\text { admission }\end{array}$ & $\begin{array}{l}\text { Readmissions, } \\
\%\end{array}$ \\
\hline 2011 & 39578 & 7.4 & 0.12 & 9.6 \\
2012 & 37033 & 7.3 & 0.12 & 10.4 \\
2013 & 41428 & 6.5 & 0.12 & 11.1 \\
2014 & 42621 & 6.8 & 0.12 & 10.3 \\
2015 & 42995 & 7.6 & 0.12 & 11.0
\end{tabular}

in antibiotic consumption without compromising patient care. As there was no significant change in oral antibiotic consumption over the intervention period, our results suggest that the main driver of inappropriate antibiotic use in our hospital was unnecessary intravenous antibiotics. Our results showing $\sim 18 \%$ reduction in antibiotic use are consistent with a systematic review of change in antibiotic prescribing for controlled before-after studies where the median reduction in antibiotic usage was $17.7 \% .^{[13]}$

Our ASP realised a $>40 \%$ reduction in direct antibiotic costs from the second year onwards, and a much smaller rise in the cost of laboratory tests despite an $8.6 \%$ increase in patient bed days from 2011 to 2015 . It is noteworthy that the $19.6 \%$ reduction in antibiotic use reported in our pilot study intervention was maintained as the ASP was rolled out to all four wards. Total cost savings are likely to be much higher than the direct costs of the antibiotics themselves when the reduction in use of consumable items such as intravenous giving sets and cannulas, as well as savings in nurses' time, are taken into account. Although we have not been able to demonstrate reductions in complications such as peripheral line infections and Clostridium difficile-associated diarrhoea (CDAD), these are strongly associated with reductions in use of intravenous therapy and broad-spectrum antibiotics.

The ASP is a multifaceted programme and it is therefore not possible to determine which of the individual features has been most successful. Our impression however has been that dedicated weekly ward rounds with AS 'champions', where fundamental principles of stewardship are reinforced, have led to an improved knowledge base, particularly in the registrar grade of doctors. Registrars rotate through the general internal medicine wards on a 3-monthly basis and many have returned for more than one rotation, which reinforces their learning. Interestingly, the medical consultants have not attended rounds despite invitation to do so, which has created an unexpected tension in that junior doctors are often better educated than their seniors when it comes to optimal antibiotic prescribing. With the continued hierarchical approach to medicine in SA, this is creating a barrier to patients receiving optimal antibiotic management. 
Our study has a number of limitations. Owing to its observational design we were unable to control for any confounding variables that may affect antibiotic prescribing. We are also unable to determine the effects of our intervention on important patient-orientated outcomes such as rates of $\mathrm{CDAD}$ or multidrug-resistant Gram-negative bloodstream infections. However, it has previously been shown that reduction in antibiotic use leads to reductions in resistance rates $^{[15]}$ and it is reasonable to assume that our intervention has had an effect in this area. A further limitation is the lack of potential reproducibility of the intervention in hospitals across SA and in other resource-limited settings. As the O'Neill report ${ }^{[12]}$ has highlighted, investment in persons practising infection-related specialties in the workplace has been poor and SA is no exception, with a severe shortage in infectious diseases specialists and microbiologists in particular. However, we would contend that AS champions who can create change and optimise antibiotic use in hospitals do not have to be limited to these role-players. To this end, two national training centres for AS have been funded, and the first 5-day trainthe-trainer course was held at Groote Schuur Hospital in July 2016. The express objective of this initiative is to address inequity of access to healthcare practitioners with expertise in AS in provinces that have limited or no infection specialists and no ASPs currently in place. The first course hosted trainees from six hospitals in the Eastern Cape, and provided practical teaching on how to set up an ASP and perform AS rounds. Follow-up visits to each hospital will help mentor teams in the development of their ASPs. The recent demonstration that a non-specialist pharmacist intervention in Netcare hospitals across SA was able to achieve similar reductions in consumption highlights the opportunity to develop a number of different ASP models within SA that could be tailored to different settings. ${ }^{[16]}$ ASPs centred around nurses have yet to be trialled, but the success of task-shifting antiretroviral treatment management from doctors to nurses in the STRETCH model, ${ }^{[17]}$ suggests that this cadre of healthcare professional could be an important addition to stewardship programmes within and outside SA.

\section{Conclusions}

The cost savings realised as a result of our ASP should be of interest to hospital, provincial and national health managers, as well as key operators in the private sector, including medical aids. ASPs can not only fund themselves, but potentially be a source of revenue to put back into infection prevention and quality improvement programmes improving patient safety related to infection. Internationally, ASPs are recognised as reducing length of hospital stay, affecting already overburdened health institutions. ${ }^{[18]}$

Future work in this area will focus on the reproducibility of our intervention in other healthcare settings, as a result of the national training programme. Additionally, further research is needed on combining different models of ASP in low-resource settings.

1. Ardal C, Outterson K, Hoffman SJ, et al. International cooperation to improve access to and sustain effectiveness of antimicrobials. Lancet 2016;387(10015):296-307. http://dx.doi.org/10.1016/S01406736(15)00470-5

2. Coetzee J, Corcoran C, Prentice E, et al. Emergence of plasmid-mediated colistin resistance (MCR-1) among Escherichia coli isolated from South African patients. S Afr Med J 2016;106(5):449-450. http://dx.doi. org/10.7196/SAMJ.2016.v106i5.10710

3. Mendelson M, Matsoso MP. The World Health Organization Global Action Plan for antimicrobial resistance. S Afr Med J 2015;105(5):325. http://dx.doi.org/10.7196/SAMJ.9644

4. Perovic O, Singh-Moodley A, Duse A, et al. National sentinel site surveillance for antimicrobial resistance 4. Perovic O, Singh-Moodley A, Duse A, et al. National sentinel site surveillance for antimicrobial resistance
in Klebsiella pneumoniae isolates in South Africa, 2010 - 2012. S Afr Med J 2014;104(8):563-568. http:// dx.doi.org/10.7196/SAMJ.7617

5. Center for Disease Dynamics, Economics and Policy. Resistance Map. http://resistancemap.cddep.org/ (accessed 12 August 2016)

6. Brink A, Coetzee J, Clay C, et al. The spread of carbapenem-resistant Enterobacteriaceae in South Africa: Risk factors for acquisition and prevention. S Afr Med J 2012;102(7):599-601. http://dx.doi.org/10.7196/ SAMJ.5789

7. Dellit TH, Owens RC, McGowan JE Jr, et al. Infectious Diseases Society of America and the Society for Healthcare Epidemiology of America guidelines for developing an institutional program to enhance antimicrobial stewardship. Clin Infect Dis 2007;44(2):159-177. http://dx.doi.org/10.1086/510393

8. Lepper PM, Grusa E, Reichl H, Hogel J, Trautmann M. Consumption of imipenem correlates with betalactam resistance in Pseudomonas aeruginosa. Antimicrob Agents Chemother 2002;46(9):2920-2925. http:// dx.doi.org/10.1128/aac.46.9.2920-2925.2002

9. Mendelson M, Rottingen JA, Gopinathan U, et al. Maximising access to achieve appropriate human antimicrobial use in low-income and middle-income countries. Lancet 2016;387(10014):188-198. http:// dx.doi.org/10.1016/\$0140-6736(15)00547-4

10. Visser A, Moore DP, Whitelaw A, et al. Global antibiotic resistance partnership situation analysis: Antibiotic use and resistance in South Africa: Part VII. Interventions. S Afr Med J 2011;101(8):587-595.

11. Levy SB, Marshall B. Antibacterial resistance worldwide: Causes, challenges and responses. Nat Med 2004;10(12 Suppl):S122-S129. http://dx.doi.org/10.1038/nm1145

12. O'Neill J. Review on antimicrobial resistance. Tackling drug-resistant infections globally. 2016. https:// amr-review.org/sites/default/files/160518_Final\%20paper_with\%20cover.pdf (accessed 7 December 2016).

13. Davey P, Brown E, Charani E, et al. Interventions to improve antibiotic prescribing practices for hospital inpatients. Cochrane Database Syst Rev 2013, Issue 4. Art. No.: CD003543. http://dx.doi. org/10.1002/14651858.CD003543.pub3

14. Boyles TH, Whitelaw A, Bamford C, et al. Antibiotic stewardship ward rounds and a dedicated prescription chart reduce antibiotic consumption and pharmacy costs without affecting inpatient mortality or rechart reduce antibiotic consumption and pharmacy costs without affecting inpatient mortality
admission rates. PLoS One 2013;8(12):e79747. http://dx.doi.org/10.1371/journal.pone.0079747

15. Friedman CR, Whitney CG. It's time for a change in practice: Reducing antibiotic use can alter antibiotic resistance. J Infect Dis 2008;197(8):1082-1083. http://dx.doi.org/10.1086/533450

16. Brink AJ, Messina AP, Feldman C, et al. Antimicrobial stewardship across 47 South African hospitals: An implementation study. Lancet Infect Dis 2016;16(9):1017-1025. http://dx.doi.org/S1473-3099(16)30012-3

17. Fairall L, Bachmann MO, Lombard C, et al. Task shifting of antiretroviral treatment from doctors to primary-care nurses in South Africa (STRETCH): A pragmatic, parallel, cluster-randomised trial. Lancet 2012:380(9845):889-898. http://dx.doi.org/10.1016/S0140-6736(12)60730-2

18. Bauer KA, West JE, Balada-Llasat JM, Pancholi P, Stevenson KB, Goff DA. An antimicrobial stewardship program's impact. Clin Infect Dis 2010;51(9):1074-1080. http://dx.doi.org/10.1086/656623 